\title{
DIE INVLOED VAN SEKERE POSSLEUTELFAKTORE OP WERKSPRESTASIE
}

G. VAN DER M. SIEBERHAGEN

DEPARTEMENT BEDRYFSIELKUNDE

\section{SUMMARY}

The relationship between 6 job "core dimensions" (variety, autonomy, task-identity, feedback, dealing with others and friendship opportunities) and the total work performance of 93 employees was investigated. No significant correlations were obtained except for the core dimension "autonomy" $(r=, 24, p<, 05)$. No statistically significant improvement in predictory work performance could be accomplished by adding the remainder of the core dimensions.

Bedryfsielkundiges stel onder andere belang in die identifisering van faktore wat daartoe aanleiding gee dat ' $\mathrm{n}$ werknemer in sy besondere pos doeltreffend funksioneer. Binne die huidige ekonomiese opset in Suid-Afrika is werksdoeltreffendheid en gepaardgaande hoër produktiwiteit van kardinale belang en is dit iets wat die aandag van wetenskaplikes, personeelbestuurders en bedryfsleiers wel deeglik verdien. Een van die faktore wat werksdoeltreffendheid moontlik kan beïnvloed is die ontwerp van 'n pos. Aanvanklik is geglo dat posontwerp so eenvoudig moontlik moet wees om doeltreffende werksprestasie te verseker. Latere navorsing dui egter daarop dat oorvereenvoudigde posontwerp ook weens die eentonigheid wat dit kan meebring, ongunstige gevolge in die vorm van ontevredenheid, verhoogde arbeidsomset en werksafwesigheid mag inhou (Hackman en Lawler, 1971; Walker, 1950).

'n Manier om bogenoemde ongewenste gevolge te vermy, is om poste te verryk of te verruim (Backer, 1973). Uit gegewens in verband met werkverryking of werkverruiming (in psigologiese sin), blyk dat werknemers in sommige gevalle wel beter presteer en groter werkstevredenheid openbaar. Dit blyk egter moeilik te wees om te verklaar wat werklik tot hierdie positiewe resultate aanleiding gee (Hackman en Lawler, 1971). Om dus enigsins tot 'n wetenskaplike ontleding van die probleem oor te gaan, behoort 'n raamwerk waarbinne die rol van posontwerp ondersoek kan word, opgestel te word.

In hierdie verband blyk die konseptuele model van Hackman en Lawler (1971) 'n stap in die regte rigting te wees, daar dit die toestande aandui waaronder 'n pos die ontwikkeling van interne motivering by die posbekleër sal aanhelp. 
Die model (skematies voorgestel in Figuur 1) maak voorsiening vir die volgende onafhanklike veranderlikes: (a) Die sterkte van die posbekleër se begeerte na hoër-ordebehoeftebevrediging en (b) die mate waarin vier sleutelfaktore (verskeidenheid, outonomie, taak-identiteit en terugvoering) in die betrokke pos aanwesig is.

Die grondgedagte soos in die model weerspieël, kom kortliks daarop neer dat, indien 'n pos in 'n groot mate bogenoemde sleutelfaktore bevat en die posbekleër ook 'n sterk begeerte na hoër-orde-behoeftebevrediging ondervind, so 'n persoon onder andere groter werkstevredenheid sal openbaar en werk van 'n beter kwaliteit sal lewer. Vir alle praktiese doeleindes gaan dit in die model om die verband tussen die aanwesigheid van sekere sleutelfaktore en sekere afhanklike veranderlikes, waaronder werksprestasie ressorteer.

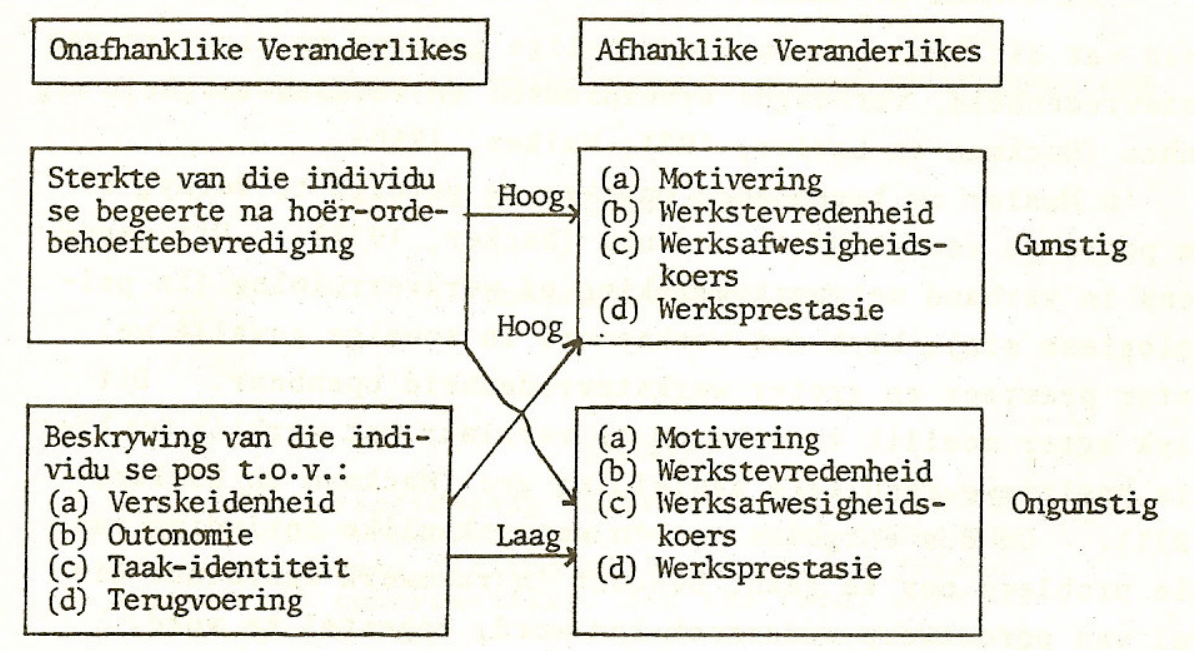

Figuur 1. 'n Skematiese voorstelling van die konseptuele model van Hackman en Lawler.

Hackman en Lawler (1971) se navorsing, waarin hierdie model empiries verifieer is, berus op 'n studie wat by 'n diensleweringsorganisasie ('n telefoonmaatskappy) uitgevoer is. Die vraag ontstaan egter hoe toepasbaar die model in ander soort organisasies is. Dit kan redelikerwys verwag word dat 'n model van hierdie aard, indien nie plekgebonde nie, dan wel kultuurgebonde kan wees. Indien die model (of sekere aspekte daarvan) byvoorbeeld in 'n Suid-Afrikaanse organisasie sou standhou, sou die algemene toepasbaarheid daarvan kan verstewig word en sou dit waarskynlik as 'n belangrike bydrae tot die vakliteratuur beskou kan word.

Teen die bostaande agtergrond is hierdie studie aangepak en meer in die besonder daarop gerig om die verband tussensekere possleutelfaktore en werksprestasie te ondersoek. 


\section{DOELSTELLINGS EN HIPOTESES}

\section{Doelstellings}

Die doelstellings van hierdie ondersoek is om deur middel van 'n korrelasiestudie die volgende vas te stel:

a) Die toepasbaarheid van die vraelys-items van Hackman en Lawler (1971) in 'n Suid-Afrikaanse organisasie.

b) Die verband tussen ses afsonderlike sleutelfaktore (verskeidenheid, outonomie, taak-identiteit, terugvoering, skakeling met ander persone en die geleentheid om vriendskapsverhoudinge aan te gaan) en totale werksprestasie. Die genoemde sleutelfaktore is ook deur Hackman en Lawler gebruik, maar hulle het geen definitiewe hipotese gestel omtrent die aanwesigheid van die laaste twee faktore nie.

c) Of sekere van bogenoemde sleutelfaktore 'n sterker bydrae tot werksprestasie lewer en of al die sleutelfaktore aanwesig móét wees om doeltreffende werksprestasie te verseker.

d) Die verband tussen die twee "interpersoonlike" sleutelfaktore (skakeling met ander persone en die geleentheid om vriendskapsverhoudinge aan te gaan), en probleemoplossingsvaardigheid as prestasiefaktor.

e) Die verband tussen tevredenheid van werknemers (bepaal volgens die metode van Porter, 1962 en 1963) totale werksprestasie.

\section{Hipoteses}

Op grond van bogenoemde doelstellings, word die volgende hipoteses gestel:

a) Die aanwesigheid van die ses possleutelfaktore hou verband met die werksprestasie van werknemers.

b) $\mathrm{Al}$ ses die possleutelfaktore moet aanwesig wees ten einde doeltreffende werksprestasie te verseker. 
c) Die aanwesigheid van die twee interpersoonlike sleutelfaktore (skakeling met ander persone en die geleentheid om vriendskapsverhoudinge aan te gaan) hou verband met die probleemoplossingsvaardigheid van werknemers.

d) Die tevredenheid (soos omlyn deur Porter 1962 en 1963) van werknemers hou verband met hulle totale werksprestasie.

\section{METODE VAN ONDERSOEK}

\section{Raamwerk waarbinne hierdie studie uitgevoer is}

Vanweë die belangstelling van die organisasie waar die studie uitgevoer is, is

a) alle beskikbare blanke werknemers (hoofsaaklik werksaam in operateursposte) by die studie betrek.

b) Vraelyste is deurgaans gebruik om inligting aangaande die ses sleutelfaktore te bekom.

c) Die ondersoek het saamgeval met die jaarlikse program van prestasiebeoordeling sodat die organisasie se eie grafiese beoordelingskaal (met enkele aanpassings) die nodige werksprestasiedata verskaf het.

d) Verder is die ondersoek voorafgegaan deur 'n intensiewe posontledings-, posbeskrywings- en poswaarderingsprogram wat deur die organisasie self onderneem is. Tydens hierdie program is onderhoude met elkeen van die werknemers wat by die ondersoek betrek is, gevoer. Die nut van die program vir die ondersoek lê daarin dat werknemers gewoonlik deeglik van die aard en omvang van hulle betrokke poste bewus is.

\section{Prosedure}

Vraelys aan werknemers. Nadat die nodige toestemming verkry is, is die items in Hackman en Lawler se vraelys (behalwe enkele byvoegings om die vrae duideliker te stel) net so oorgeneem. 'n Afrikaanse vertaling van die vraelys is ook opgestel.

Die vraelys wat deur werknemers voltooi is, bestaan uit drie afdelings:

Afdeling A. Hier moet persone op 10 items, waarvan 7 benut word (aangesien slegs dié 7 items met die betrokke sleutelfaktore verband hou), 'n aanduiding op 'n sewepunt-skaal gee van die aanwesigheid van sekere eienskappe in hulle werk. 
Afdeling B. Hier moet persone sekere biografiese gegewens (ouderdom, opvoedkundige kwalifikasies, professionele kwalifikasies en aantal poste in ander organisasies gevul) verstrek.

Afdeling C. Hierdie afdeling is soortgelyk aan Afdeling A, behalwe dat persone by elk van 20 items, waarvan 11 benut word (aangesien slegs dié 11 items met die betrokke sleutelfaktore verband hou) ook 'n aanduiding moet gee van hoeveel van elke eienskap hulle graag in hulle poste aanwesig wil hê. Met die uitsondering van die sleutelfaktor "skakeling", moes eike werknemer twéé keer 'n aanduiding gee van die mate waartoe elke eienskap verlang word.

Drie-en-negentig werknemers wat in 10 verskillende poste werksaam is, het die vraelyste voltooi.

Prestasiebeoordelings. Die beoordelingstelsel bestaan uit vier faktore, elk met 'n grafiese vyfpunt-beoordelingskaal. Aangesien Hackman en Lawler (1971) die moontlikheid voorsien dat die twee interpersoonlike sleutelfaktore (skakeling met ander persone en die geleentheid om vriendskapsverhoudinge aan te gaan) die probleemoplossingsvaardigheid van werknemers mag beïnvloed, is met toestemming van die bestuur van die organisasie die faktor "probleemoplossingsvaardigheid" in die beoordelingskaal ingevoeg.

Twintig toesighouers het vervolgens die 93 werknemers beoordeel, waarna die beoordelings individueel met die betrokke werknemers bespreek is. Daarna het die afdelingshoofde hulle "goedkeuring" aan die beoordelings verleen. (Die prestasiebeoordelings is later deur die organisasie vir doeleindes van salarisaanpassings benut.)

\section{RESULTATE EN BESPREKING}

\section{Biografiese gegewens}

Uit reaksies op die vier biografiese items (opvoedkundige kwalifikasies, professionele kwalifikasies, ouderdom en aantal poste in ander organisasies gevul) blyk dit dat die 93 werknemers slegs t.o.v. professionele kwalifikasies beduidend verskil $(\mathrm{p}<0,01)$. Professionele kwalifikasies in hierdie verband dui op tegniese diplomas en sertifikate wat deur werknemers verwerf is, terwyl opvoedkundige kwalifikasies (ten opsigte waarvan geen beduidende verskil is nie) verwys na skool- en universiteitsopleiding. Aangesien 'n aantal van die werknemers nog besig is om met verdere studies hul professioneel te bekwaam (en hierdie inligting nie akkuraat in die data weer- word nie) is groepe wel as homogeen aanvaar kan word. 
Mate waarin sleutelfaktore in werk aanwesig is

Voordat enige verdere verwerkings van gegewens gedoen is, was dit wenslik om vas te stel hoe bestendig die werknemers die vrae met betrekking tot die mate waarin sleutelfaktore in die werk aanwesig is, beantwoord het.

'n Ontleding van werknemers se herhaalde beoordelings lewer die resultate soos uiteengesit in Tabel 1.

TABEL 2

Betroubaarheid van Beoordeling van 93 Werknemers

t.0.v. 6 Sleutelfaktore in hul onderskeie Poste

\begin{tabular}{|c|c|c|c|c|}
\hline & & & & \\
\hline \multirow[b]{2}{*}{ Sleutelfaktor } & \multicolumn{4}{|c|}{ Korrelasie tussen Herhaalde Beoordelings } \\
\hline & $\begin{array}{l}\text { Beoordeling } \\
\text { (1) en (2) }\end{array}$ & $\begin{array}{l}\text { Beoordeling } \\
\text { (2) en (3) }\end{array}$ & $\begin{array}{l}\text { Beoordeling } \\
\text { (1) en (3) }\end{array}$ & $\begin{array}{l}\text { Beoordeling } \\
\text { (3) en (4) }\end{array}$ \\
\hline Verskeidenheid &, $51^{* * *}$ &, $69^{* * *}$ &, $67^{* * *}$ & - \\
\hline Outonomie &, $40^{* * *}$ &, $28^{* * *}$ &, $41^{* * * *}$ & - \\
\hline Taak-identiteit & 01 &, $39^{* * * *}$ &, $35^{* * *}$ & - \\
\hline Terugvoering & $\infty$ & - & - &, $33^{*+\%}$ \\
\hline Skakeling &, $45^{* * *}$ & - & - & - \\
\hline $\begin{array}{l}\text { Vrienskapsverhou- } \\
\text { dinge }\end{array}$ & $.25^{*}$ & 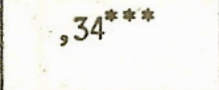 &, 10 & - \\
\hline$p<, 05$ & & * $\mathrm{p}<, 01$ & & $* * * ;<$ \\
\hline
\end{tabular}

Opmerkings. (a) Terugvoering: Ander korrelasies word nie aangedui nie, aangesien beoordelings gedoen is ten opsigte van verskillende dimensies van terugvoering. (b) Skakeling: Slegs twee beoordelings is gedoen. (c) Beoordeling: (1) verwys na Afdeling A van die vraelys, (2), (3) en (4) verwys na Afdeling C van die vraelys. (d) Vir verskeidenheid, outonomie, taak-identiteit en vriendskapsverhoudinge is slegs drie beoordelings gedoen.

Uit die tabel blyk dit dat vir die 14 interkorrelasies wat hier van belang is, nege beduidend is op die 0,1\%-peil, twee beduidend is op die $1 \%$-peil, een beduidend is op die $5 \%$-peil en twee onbeduidend is. Die verkreë interkorrelasies (hoewel nie besonder hoog nie) dui aan dat die beoordelings betroubaar genoeg is om by verdere berekenings benut te word.

Mate waarin sleutelfaktore in werk verlang word

'n Ontleding van betroubaarheid van hierdie beoordeling word in Tabel 2 weergegee. 
TABEL 2

Betroubaarheid van Beoordeling ( $\mathrm{N}=93$ ) van die Mate

waarin elke Sleutelfaktor aanwesig behoort te wees

\begin{tabular}{|l|c|}
\hline \multicolumn{1}{|c|}{ Sleutelfaktore } & $\begin{array}{c}\text { Korrelasie (r) tussen } \\
\text { beoordelings }\end{array}$ \\
\hline Verskeidenheid &, $62^{*}$ \\
Outonomie &, 08 \\
Taak-identiteit &, $53^{*}$ \\
Terugvoering &, $34^{*}$ \\
Skakeling & $-^{* *}$ \\
Vriendskapsverhoudinge &, $39^{*}$ \\
\hline
\end{tabular}

" $\mathrm{p}<, 001$

* *slegs een beoordeling

Uit bostaande tabel blyk dat, hoewel $r$ ten opsigte van items in verband met outonomie onbeduidend is, beoordelings ten opsigte van die vier ander sleutelfaktore wel as betroubaar beskou kan word.

Verband tussen interpersoonlike sleutelfaktore en probleemoplossingsvaardigheid

Die korrelasies tussen skakeling met ander, die geleentheid om vriendskapsverhoudinge aan te gaan en probleemoplossingsvaardigheid, word in Tabel 3 weergegee.

TABEL 3

Korrelasie tussen Sleutelfaktor

en Probleemoplossingsvaardigheid $(\mathrm{N}=91)$

\begin{tabular}{|l|c|}
\hline \multicolumn{1}{|c|}{ Sleutelfaktor } & r \\
\hline Skakeling &, 17 \\
Vriendskapsverhoudinge &, 14 \\
\hline
\end{tabular}

Nie een van dié korrelasies is beduidend nie. Die gevolgtrekking moet gemaak word dat daar geen beduidende verband tussen die interpersoonlike sleutelfaktore en probleemoplossingsvaardigheid bestaan nie.

\section{Verband tussen afsonderlike sleutelfaktore en totale werksprestasie}

Die hipotese is gestel dat die aanwesigheid van die ses sleutelfaktore ' $n$ invloed uitoefen op die prestasie van werknemers. In Tabel 4 word 'n ontleding van die verband tussen die ses afsonderlike sleutelfaktore en totale werksprestasie aangegee. 
Hieruit blyk dat: (a) Behalwe wat die sleutelfaktor "outonomie" betref, bestaan daar geen beduidende korrelasie tussen die afsonderlike waargenome sleutelfaktore en totale werksprestasie nie. (b) Alhoewel die korrelasies tussen die verskillende sleutelfaktore en totale werksprestasie so klein is, neig almal in 'n positiewe rigting.

TABEL 4

Korrelasie Tussen Afsonderlike

Sleutelfaktore en Totale Werksprestasie ( $N=93$ )

\begin{tabular}{|l|c|}
\hline \multicolumn{1}{|c|}{ Sleutelfaktor } & $\mathrm{r}$ \\
\hline Verskeidenheid &, 16 \\
Outonomie &, $24^{*}$ \\
Taak-identiteit &, 07 \\
Skakeling &, 03 \\
Vrienskapsverhoudinge &, 17 \\
\hline
\end{tabular}

${ }^{*} \mathrm{p}<, 05$

\section{Verband tussen tevredenheid en totale werkstasie}

Die tevredenheid van 'n werknemer word deur Porter (1962 en 1963) uitgedruk as die verskil tussen wat elke persoon ten opsigte van elke sleutelfaktor graag in sy pos wil hê en wat op die oomblik in sy pos aanwesig is.

Die hipotese is gestel dat hoe kleiner hierdie verskil is (dit wil sê, hoe meer tevrede die persoon is), hoe beter behoort die persoon te presteer. Uit Tabel 5 blyk dit egter dat daar, wat hierdie groep werknemers betref, geen beduidende verband tussen tevredenheid en totale werksprestasie bestaan nie. Op sigself is hierdie bevinding een van talle herbevestigings van 'n verskynsel wat twee dekades gelede deur Brayfield en Crockett (1955) empiries nagevors is.

TABEL 5

Verband Tussen Tevredenheid

en Totale Werksprestasie

\begin{tabular}{|l|r|}
\hline \multicolumn{1}{|c|}{ Sleutelfaktore } & \multicolumn{1}{c|}{$r$} \\
\hline Verskeidenheid & 0,02 \\
Outonomie & $-0,01$ \\
Taak-identiteit & $-0,02$ \\
Terugvoering & $-0,04$ \\
Skakeling & 0,03 \\
Vriendskapsverhoudinge & $-0,07$ \\
\hline
\end{tabular}




\section{Meervoudige korrelasie tussen totale werksprestasie en die ses possleutelfaktore}

Aangesien die ses sleutelfaktore almal verband hou met die kriterium (totale werksprestasie), is besluit om 'n meervoudige korrelasie te bepaal, ten einde die optimum geweegde korrelasie tussen die ses sleutelfaktore en die kriterium te vind.

Die meervoudige korrelasie gee die hoogste korrelasie wat deur enige geweegde kombinasie van die ses sleutelfaktore met die kriterium (werksprestasie) in hierdie geval gevind kan word. ' $\mathrm{n}$ Verkreë $\mathrm{R}=, 442(\mathrm{p}<, 05)$ dui daarop dat in hierdie geval die ses possleutelfaktore, gesamentlik ingespan, nie as basis vir die voorspelling van werksukses gebruik kan word nie. As dit in aanmerking geneem word dat hier ses voorspellers betrokke is en dat die berekening van R slegs op 93 werknemers gebaseer is, kan dit verwag word dat $\mathrm{R}$ vir groter groepe aansienlik sal krimp. 'n Skatting van hierdie effek (Nunnally, 1967, p.164) dui daarop dat $\mathrm{R}=, 342$ waarskynlik sal krimp na $\mathrm{R}=, 258$ by hertoepassing op groter groepe.

Ten einde te bepaal of een of enkele van die sleutelfaktore nie naastenby dieselfde bydrae tot voorspelling van variansie in die kriterium lewer nie, is die metode van byvoeging van voorspellers (Nunnally, 1967, p.170) gevolg.

Uit die berekening blyk dit dat byvoeging van enige sleutelfaktor tot die sleutelfaktor "outonomie" geen statisties beduidende toename in $\mathrm{R}$ veroorsaak nie. (Die faktor "vriendskapsverhoudinge" wat die grootste addisionele bydrae tot R maak, toon 'n "onbeduidende" semi-parsiële korrelasie van ,151 met die kriterium). Uit die bogenoemde gegewens blyk dit dat "outonomie" die beste voorspeller van werksprestasie in hierdie besondere situasie is. Dit sou dus miskien wenslik wees om poste so te verander dat werknemers meer outonoom kan optree.

Uit die resultate van hierdie ondersoek blyk dus die volgende:

a) Die hipotese dat die ses sleutelfaktore afsonderlik, soos waargeneem deur die 93 werknemers, 'n invloed uitoefen op hul totale werksprestasie, moet verwerp word. Die uitsondering is die sleutelfaktor outonomie.

b) Die hipotese dat al ses sleutelfaktore aanwesig moet wees ten einde doeltreffende werksprestasie te verseker, moet verwerp word.

c) Die hipotese dat die twee interpersoonlike sleutelfaktore (skakeling met ander persone en die geleentheid om vriendskapsverhoudinge aan te gaan) 'n invloed 
uitoefen op die probleemoplossingsvaardigheid van werknemers, moet verwerp word.

d) Die hipotese dat die tevredenheid van werknemers ' $n$ invloed op totale werksprestasie uitoefen, moet verwerp word.

Hierdie gevolgtrekking word egter gekwalifiseer deur:

i) Die wyse waarop tevredenheid in hierdie ondersoek bepaal is. Tevredenheid word hier (in navolging van Porter 1962 en 1963) uitgedruk as die verskil tussen die mate waarin elke persoon graag elke afsonderlike sleutelfaktor in sy besondere pos aanwesig wil sien en die mate waarin dit tans aanwesig is. Hoe kleiner hierdie verskil, hoe meer dui dit daarop dat 'n persoon tevrede is met die mate waarin die betrokke sleutel-faktor aanwesig is binne sy pos. Dit mag egter voorkom dat ' $n$ persoon baie meer van 'n sekere eienskap in sy werk aanwesig wil hê as waarvoor die skale voorsiening maak.

ii) Die feit dat dit hier bloot gaan om die tevredenheid met die aanwesigheid van die ses sleutelfaktore. Ander aspekte van die werksituasie wat ook tevredenheid mag beïnvloed, is nie by hierdie ondersoek betrek nie.

e) Die resultate van hierdie ondersoek toon dat die ses sleutelfaktore in hierdie situasie nie soveel gewig dra as wat Hackman en Lawler (1971) daaraan toeken nie. Hierdie gevolgtrekking word egter ook gekwalifiseer deur die volgende feite: i) Hackman en Lawler ken 'n sentrale rol toe aan die sterkte van die begeerte na hoër-orde-behoeftebevrediging. (Vergelyk Figuur 1). In hierdie ondersoek is geen aandag aan hierdie aspek geskenk nie.

ii) Die faktore op grond waarvan werksprestasie beoordeel is, verskil van dié deur Hackman en Lawler (1971) gebruik.

iii) Die monster (93 werknemers) by hierdie ondersoek mag miskien te klein wees. Die monster in die geval van Hackman en Lawler se ondersoek bestaan uit 208 werknemers.

f) Die waarde van hierdie ondersoek lê moontlik daarin dat 'n sekere persentasie van die variansie $( \pm 12 \%)$ in werksprestasie wel verklaar word deur die aanwesigheid van die ses sleutelfaktore in poste. Verder blyk dit dat veral die faktor "outonomie" relatief van groter belang is. 


\section{GEVOLGTREKKING}

a) Ten einde resultate vergelykbaar te maak, is dit noodsaaklik dat by enige verdere navorsing in verband met die ses sleutelfaktore soos in hierdie ondersoek geïdentifiseer, dieselfde vraelys-items deurgaans gebruik word.

b) Die aanduidings van werknemers ten opsigte van die aanwesigheid van sleutelfaktore in hulle poste behoort gekontroleer te word. Vir hierdie doel kan toesighouers identiese vraelys-items, wat betrekking het op poste waaroor hulle toesig hou, voltooi (Hackman en Lawler, 1971, p.266).

c) Ten einde prestasiebeoordelings te kontroleer, behoort toesighouers ook versoek te word om werknemers in ' $n$ rangorde te plaas (Hayden, 1971, p.612). Laasgenoemde prosedure was nie in hierdie ondersoek uitvoerbaar nie.

d) Dit word aanbeveel dat " $n$ alternatiewe metode vir die vasstel van die sterkte van die begeerte na hoër-orde-behoeftebevrediging ontwikkel word. Alleenlik dán kan die konseptuele model van Hackman en Lawler aan 'n volledige en deeglike toets onderwerp word.

e) Ander sleutelfaktore wat ook 'n invloed uitoefen op werksprestasie, behoort geïdentifiseer te word.

f) In hierdie ondersoek is geen aandag geskenk aan die invloed van persoonlikheidseienskappe (Porter en Lawler, 1968) en die agtergrond van werknemers (Hulin en Blood, 1968) op die verband tussen die aanwesigheid van die ses possleutelfaktore en werksprestasie nie. By verdere ondersoeke behoort hierdie aspekte aandag te geniet.

\section{OPSOMMING}

Die verband tussen 6 possleutelfaktore (verskeidenheid, outonomie, taak-identiteit, terugvoering, skakeling met ander persone en die geleentheid tot vriendskapsverhoudinge en die totale werksprestasie van 93 werknemers, is ondersoek.

Behalwe vir die sleutelfaktor outonomie $(r=, 24, p<, 05)$ is geen beduidende korrelasie gevind nie. Die oorblywende possleutelfaktore kon nie beduidend hierop verbeter nie. 


\section{VERWYSINGS}

Backer, W. Werkverryking: 'n Model van Werksontwerp wat voortspruit uit die MotiveringsHigiëne Teorie van Herzberg. Pretoria: Referaat gelewer tydens die Twaalfde Kongres van S.I.R.S.A., September 1973.

Brayfield, A.H. \& Crokett, W.H. Employee attitudes and employees performance. Psychological Bulletin, 1955, 52, 396-424.

Du Toit, J .M. Statistiese Metodes. Stellenbosch: Kosmo-Uitgewery. 1966.

Guilford, J.P. Fundamental Statistics in Psychology and Education. New York: McGrawHill. 1965.

Hackman, J.R. \& Lawler, E.E. Employee reactions to job characteristics. Journal of Applied Psychology, 1971, 55(3), 259-286.

Hayden, R.J. Performance appraisal: A better way. Personnel Journal, 1973, 52(7), 606-613.

Hulin, C.L. \& Blood, M.R. Job enlargement, individual differences and worker responses. Psychological Bulletin, 1968, 69(1); 41-55.

Nunnally, J.C. Psychometric Theory. New York: McGraw-Hill, 1967.

Poter, L.W. Job attitudes in management: I. Perceived deficiencies in need fulfillment as a function of job level. Journal of Applied Psychology, 1962, 46, 375-384.

Porter, L.W. Job attitudes in management: II. Perceived importance of needs as a function of job level. Journal of Applied Psychology, 1963, 47(2), 141-148.

Porter, L. W. \& Lawler, E.E. Managerial Attitudes and Performance. Homewood, Illinois: Irwin, 1968.

Roscoe, J.T. Fundamental Research Statistics for the Behavioral Sciences. New York: Holt, Rinehart and Winston, 1969.

Turner, A.N. \& Lawrence, P.R. Industrial Jobs and the Worker. Boston: Harvard University Graduate School of Business Administration, 1965.

Vroom, V.H. Work and Motivation. New York: Wiley, 1964.

Walker, C.R. The problem of the repetitive job. Harvard Business Review, 1950, 28(3), 5458. 